stick of ebonite near it, without producing any effect on the pointer.

Again, these two clear glass shades, belonging to gold-leaf electroscopes, are one of them coated with our varnish, and the other not. Which is the uncoated one is at once apparent from the alteration produced in the deflection of the gold leaves when I approach a stick of rubbed ebonite near the lower part of the glass shade of the uncoated one, for no such change in the deflection is produced, as you see, when the ebonite rod is brought near the glass shade, which is protected by a layer of this varnish applied on the inside.

\section{THE CURRENTS IN THE GREAT LAKES OF NORTH AMERICA.}

A PAPER, entitled "The Currents of the Great Lakes," prepared by Prof. Mark W. Harrington, from data collected by means of bottle-papers during the navigation seasons of 1892 and 1893, has just been published by the U.S. Department of Agriculture as a Weather Bureau Bulletin. We reprint some of the more interesting parts of the paper, and reproduce a map showing the results of the inquiry.

Early in 1892 the Weather Bureau published a wreck chart of the Great Lakes, prepared in the winter of $189 \mathrm{I}-92$. The wrecks noted on this chart were only those due to meteorological agents, and a striking feature of the chart was the clustering of wrecks in certain parts of the surface of the lakes. This suggested that unknown currents might play a considerable part in wreckage, and steps were at once taken to get some idea of what these currents are.

The method pursued was that of bottle-papers, which have frequently been used to study ocean currents, but had not been employed in the lakes, and is as follows:-A bottle, containing a paper on which is written the time and place of floating, is thrown overboard at some definite point, left to float freely, and when picked up the enclosed paper is marked with the time and place of finding. In this way two points in the line of curren are obtained, and by considering a very large number of these, satisfactory conclusions can be drawn as to the currents which convey the bottles.

A large number of bottles were specially made for this purpose, with the name of the Bureau blown into the glass. They were of an unusual colour, but the contents could be easily seen by anybody who picked them up. The weight of a bottle was about 420 grams; total external displacement, 460 cubic centimetres; volume displaced when floating, 430 c.c. ; volume exposed above water, 30 c.c.

From the position of flotation it appears that enough of the bottle was above the surface of the water to give the wind some power in drifting it. This would probably make little difference with the direction of the drift, for the wind that drifted the bottles would drift the surface water in the same direction. It may have made some difference in the speed with which the bottles travelled, making them move, perhaps, faster than the water, but this effect would be slight. Within each bottle a franked envelope was placed, addressed to the chief of the Weather Bureau, at Washington. Before a bottle was thrown overboard a blank form in the envelope had to be filled up, giving the name of the vessel and its captain, the date of floating, and the place where floated. Another space was left tor the finder to insert similar data.

The bottles actually picked up were, for the most part, on shore, very few of them having been found in the water. It is impossible to say what proportion of the bottles was recovered, but it was not great. Though probably more than five per cent., it did not exceed ten per cent. The figures cannot be given exactly, because it is not known how many of the bottles are still in the hands of masters of vessels. A considerable portion of the papers recovered was found on the Canadian shore, and, curiously, a large number of them came from shores which are for the most part uninhabited.

The investigation covers the years 1892 and 1893 , but it must be remembered that the observations could be taken only during the season of navigation. This practically limits the conclusions to the summer months, as when the bottles are floated in the spring they will probably be found in the autumn, and those that are floated in the autumn will be lodged in ice, and their routes be variously changed, so that trustworthy conclusions cannot be drawn from them. In general, the finds of NO. I $27 \%$, VOL. 49] the latter sort - that is to say, the fincis of bottles floated in the autumn and picked up in the spring-have been left out of consideration. The currents shown in the accompanying map are herefore those of the season of navigation, and practically the currents of summer.

\section{Classification of the Currents.}

The currents in the Great Lakes can be grouped under the four following heads :-

(I) The Body Currents. - These lakes all have an outflow, and there must be a general motion of the water towards the outlet. This is visible upon the map of each lake, and the currents which result from it must be continuous throughout the year, and must affect most of the water.

(2) A Surface Current due to the Prevailing Winds.-That the winds have great effect on the currents in large bodies of water is widely recognised, and the more constant they are the more marked is the effect. The westerly winds, in case of lakes lying nearly east and west, cause a surface current from the west which is in the same direction as the body current. In the case of the lakes which lie across the direction of the wind, the surface drift is from the west across the lake. The details of the direction, however, depends on where the outlet is, on the form of the lake, and on the position of the inlet.

(3) The Return Currents. - It will be seen from the illus. tration that, in the case of three of the lakes, the main currents hug cne shore. In the case of Lake Superior, it is on the southern shore; in the case of Lake Michigan, it is on the eastern shore ; and in that of Lake Huron, it is on the western shore. Lakes Erie and Ontario do not show this phenomenon so plainly. This feature can be explained by the two sorts of currents already mentioned, combined with the lay of the lakes as to the prevailing direction of the wind and the position of the outlet. In any case, however, the drive of the water from one end of the lake to the other necessitates more or less a return current, providing the outlet is not sufficiently large to allow this water to pass through. In the Great Lakes, the outlets are comparatively small, hence in all these cases there are return currents.

(4) Surf Motion.-Owing to this motion, the bottles have been found to show a decided tendency shoreward whenever they came within its vicinity, and especially so when the water was shallow.

\section{VELOCITIES OF THE CURRENTS.}

The directions of currents can be ascertained with much more precision by means of bottle-papers than can the velocities. It has therefore been very difficult to arrive at any satisfactory conclusions concerning the speed of the currents in the Great Lakes. In a general way, the speed appears to vary from four to twelve miles a day. In a few special cases, very much higher velocities have been found, but these are probably due to surf motion rather than the motion of the surface water as a whole. It is not at all improbable that the general surface motion of the lakes has a higher velocity than from four to twelve miles a day, but the only conclusion which it seems safe to draw from the data is that the velocities are at least as high as the figures mentioned.

\section{LAKe Superior,}

In this lake thirty- five bottles were recovered in 1892 , and the same number in 1893. From the courses of the bottles it appears that there is a general surface current along the south shore of the lake, from the Apostle Islands eastward, and that to the east of Kew eenaw Point this eastern current has very great breadth. Still further eastward, tow ard the eastern end of the Lake, it spreal's out in a fan-shaped way, and a branch of it seems to pass to the northward and westward, reaching the extreme northern coast of the lake. A branch of this current also turns southerly round Kewcenaw Point, and at the bottom of the bay, on the south coast of the lake, an eastern current is taken up, which joins the main current to the eastward of Marquette, Michigan. The minimum velocity of the main eastward current of the lake appears to be from four to six miles a day.

\section{Lake Michigan.}

In this lake 163 bottles were recovered in 1892 , and thirty-five in 1893 . The currents indicated by the floating of the bottles are of unusual interest. There is first a 
strong and well-marked current up the eastern coast, passing between the Maniton Islands and the Michigan mainland, and ending in the reefs and rocks to the north of Little Traverse Bay. There is a current down the west coast, but at some distance offshore. In the space between its margin and the shore there are varying currents, sometimes to the northward and sometimes to the southward - on the whole rather from the south than from the north. There is a great but gentler whirl about Beaver Island in a direction contrary to the hands of a watch. The velocities found in these currents are greater than those found in Lake Superior, and this is especially true of the northern end of the current, which passes up along the east coast. In the case of the bottles which crossed Lake Michigan, the velocities obtained in the best cases varied from four to four and a half miles a day. Taking only the bottles which passed between Maniton Islands and the mainland, the velocities obtained varied from six and a half to ten a day. developed at no great distance from the south coast, and much farther from the north coast, which is cut by two long points extending out to about one-third of its width.

\section{LAKE ONTARIO.}

In Lake Ontario 56 bottles were recovered, of which 55 belonged to the season of 1892 , and one to that of 1893 . The directions taken by the bottles in the lake are somewhat similar to those in Lake Erie, but quite distinct from those of the upper lakes. There is a general current extending diagonally across the lake from opposite the mouth of Niagara River to the outlet near Kingston. The bottles exhibited a strong tendency to seek the east colst, passing down into the bay on which Sacketts Harbour, N.Y., is situated. There are evidences of a whirl in the western end of the lake, west of the meridian of Toronto.

The general conclusions of the paper relate only to the

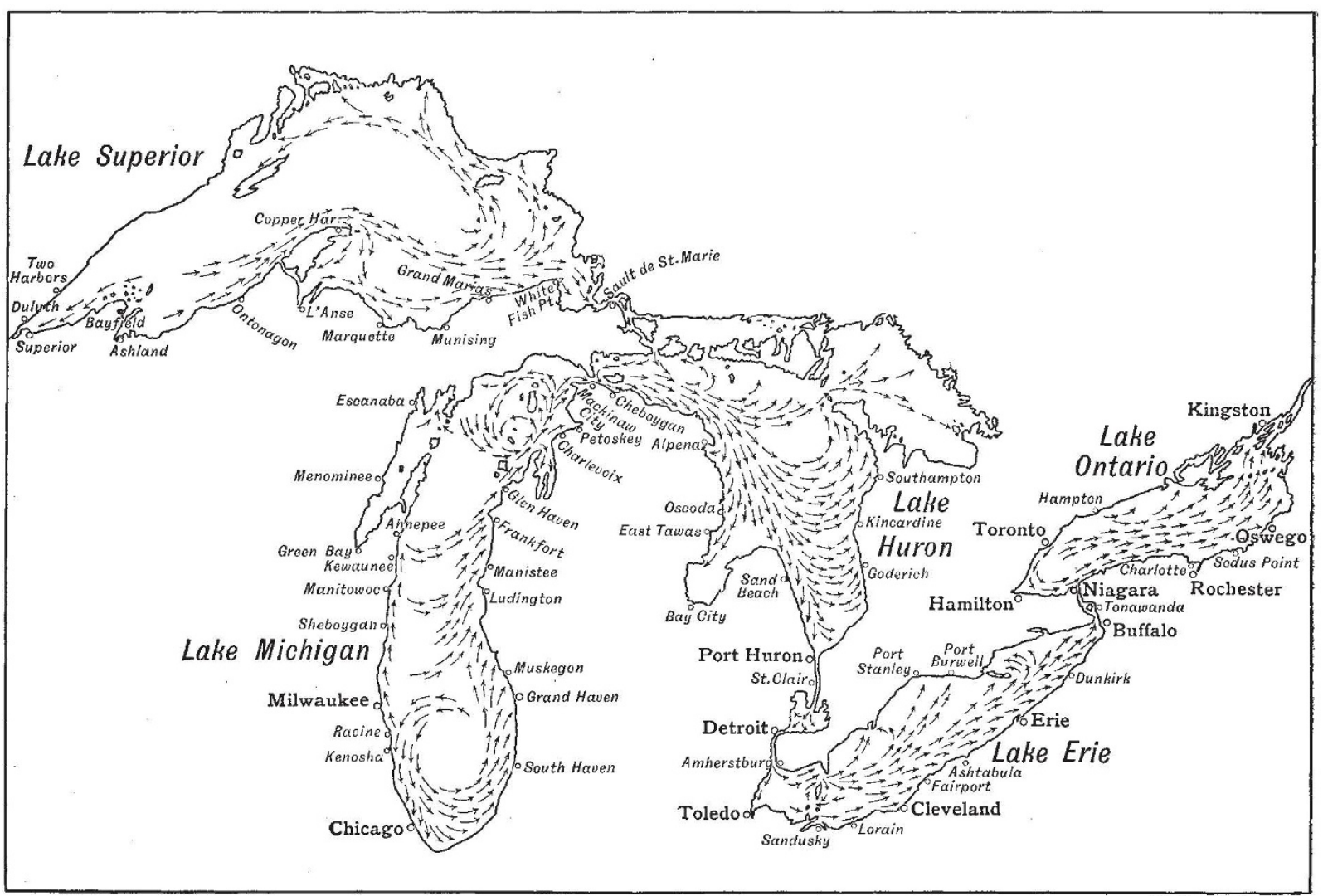

Thalker of Boutall se.

LAKE HURON.

In this lake 186 bottles were recovered, 142 for the season of I892, and forty-four for 1893 . From the courses of the bottles, it is concluded that the arrangements of currents is very much like that of Lake Mishigan. In this case, however, it seems that the main current is along the west coast, while in Lake Michigan it is along the east coast. It is found that in Lake Huron there is a strong current passing down the west coa-t and some little distance out, the whole length of the lake, turning on itself near the point of the lake, and passing up the east coast, possibly turning again along the north shore and rejoining the other current in the vicinity of Bois Blanc Island. A branch of this return extends into Georgian Bay.

\section{LAKE ERIE.}

The number of bottles recovered in Lake Erie was 96, of which 66 belonged to the season of 1892 , and 30 to 1893 . The general course of these bottles was ea,tward along the axis of the lake, with a tendency from point to point toward the coast. The indications are that the main current along the axis is best greater currents of the lakes. These currents must be sub stantially as indicated by the five or six hundred bottle-papers which have been recovered. There will, however, be some modifications due to season and direction of wind, but these modifications will be superficial, while the regular currents of the Great Lakes, which are described above, must be fairly persistent. Many of the modifications will be found in the bays and at the extreme angles of the lakes, and these remain for further investigation.

\section{SCIENTIFIC SERIALS.}

L'Anthropologie, tome v. No. I, January-February.-M. Emile Cartailhac contributes certain new facts with regard to the prehistoric history of the Pyrenees ; in the present number he describes some quartzites of the St. Acheul type that have been recently found in the cave of Herm (Ariège). The examin. ation of the animal remains was confided to M. Marce!lin Boule who com municates a short note on the remains of the Glutton (Gulo luscuss) and the Cave Lion (Felis spelaea) which were found No. 1277 , VOL. 49] 